\title{
Silent atrial fibrillation is associated with P-wave duration index in patients with cardiac resynchronisation therapy
}

Abdullah Orhan Demirtas ${ }^{1}$, Yahya Kemal Icen ${ }^{1}$, Yurdaer Donmez ${ }^{1}$, Hasan Koca ${ }^{1}$, Onur Kaypakli², Mevlut Koc ${ }^{1}$

${ }^{1}$ Cardiology Department, Health Sciences University, Adana City Hospital, Adana, Turkey ${ }^{2}$ Cardiology Department, Faculty of Medicine, Mustafa Kemal University, Hatay, Turkey

Submitted: 18 March 2019

Accepted: 25 April 2019

Arch Med Sci Atheroscler Dis 2019; 4: e74-e81

DOI: https://doi.org/10.5114/amsad.2019.85375

Copyright (c) 2019 Termedia \& Banach

\section{Abstract}

Introduction: Atrial fibrillation (AF) attacks can be silent, symptomatic, or emerge with its complications in pacemaker-implanted patient groups. P-wave duration index (PWDI), a novel parameter, is calculated by dividing the P-wave duration (PWD) by the PR interval. This study aimed to investigate the relation between PWDI and silent AF development in cardiac resynchronisation therapy defibrillator (CRT-D)-applied patients.

Material and methods: The study population consisted of 181 CRT-D device-implanted patients. Atrial fibrillation attacks that last at least $30 \mathrm{~s}$ with no symptoms were accepted as silent AF.

Results: Patients were separated into two groups: "with silent AF" and "without silent AF". The without silent AF group comprised 121 patients (mean age: $62.9 \pm 8.7$ years, $62 \%$ male). The with silent AF group included 60 patients (mean age: $67.9 \pm 9.7$ years, $60 \%$ male). The silent AF group had significantly higher mean age $(p=0.001)$. PR duration was significantly higher in the without silent AF group $(p=0.001)$. Patients with first-degree $I A B$ and $P W D I$ values were significantly higher in the with silent $A F$ group ( $p$-values were 0.001 and $<0.001$, respectively). Age $(\mathrm{OR}=1.073,95 \% \mathrm{Cl}$ : $1.028-1.119, p=0.001)$ and PWDI (OR $=1.053,95 \% \mathrm{Cl}: 1.028-1.078, p<$ 0.001 ) were detected as independent predictors for silent AF in the binomial logistic regression analysis. In the ROC analysis, a PWDI cut-off value of 0.67 determined silent AF with $81.7 \%$ sensitivity and $51.4 \%$ specificity (AUC = $0.701, p<0.001$ ).

Conclusions: P-wave duration index was significantly associated with silent $A F$ in patients with CRT-D.

Key words: cardiac resynchronisation therapy, PR interval, P-wave duration, silent atrial fibrillation.

\section{Introduction}

Cardiac resynchronisation therapy defibrillation (CRT-D) is recommended as a class I indication in symptomatic patients treated with optimal medical therapy with sinus rhythm, ejection fraction $(E F) \leq 35 \%$, and complete left bundle branch block conditions. This therapy has positive effects on mortality and morbidity in patients with heart failure with reduced ejection fraction (HFrEF) [1].

\author{
Corresponding author: \\ Abdullah Orhan Demirtas \\ Cardiology Department \\ Health Sciences \\ University \\ Adana City Hospital \\ Adana, Turkey \\ Phone: +90 5333109448 \\ E-mail: aorhandemirtas@ \\ gmail.com
}


Atrial fibrillation (AF) is a cardiac arrhythmia characterised by no recognisable $P$ wave and irregular $\mathrm{R}-\mathrm{R}$ interval on electrocardiogram (ECG). Its frequency is $3 \%$ over 20 years [2]. There must be at least $30 \mathrm{~s}$ of attack for AF diagnosis [3]. This attack can be symptomatic or asymptomatic (silent) in patients [4]. Silent AF may be very frequent in elderly and HF patient groups.

CRT-D devices are used in the treatment of HF patient groups. They also can record the cardiac arrhythmias. Atrial fibrillation attacks are frequent in CRT-D-implanted HF patients because of risk factors such as left atrial dilatation (LAE), P-wave dispersion (Pdisp), increased left atrial volume index (ILAV), and especially left ventricle (LV) dilatation.

Atrial fibrillation attacks can be silent, symptomatic, or emerge with its complications in pacemaker-implanted patient groups [5]. The cumulative yearly incidence of AF can be $30-40 \%$ in these patients. Silent AF attacks are as frequent as symptomatic ones in this group, but there are limited data about its predisposing risk factors in the literature $[6,7]$.

Increased P-wave duration and prolonged PR interval in leads DII, DIII, and aVF of a surface ECG are defined as diagnostic criteria of left atrial anomaly [8-10]. P-wave duration index (PWDI) has been described for the first time, which is calculated by dividing the P-wave duration (PWD) by the PR interval [11]. It was reported that recurrence is higher in AF ablated patients with increased PWDI. This parameter is obtained by dividing the P-wave duration, which is the indicator of the atrial conduction, by the PR interval, which is the time taken by the electrical signals to travel from the atrium to the atrioventricular node, and it reflects the conduction heterogeneity, which was thought to be a parameter for predicting silent AF detection.

This study aimed to investigate the relation between PWDI and silent AF development in CRT-Dapplied patients.

\section{Material and methods}

\section{Patient population}

Permission for this study was obtained from the Local Ethics Committee. Between 2010 and 2016, 301 patients underwent CRT-D implantation in our clinic. Of these, 62 patients had symptomatic AF attacks. Death was observed in 10 patients for any reason. We excluded 15 patients with atrial pacing because the PR interval can be changed by the device. Nineteen patients with chronic diseases were also excluded (such as chronic kidney disease, cerebrovascular diseases, chronic obstructive lung disease). These patients were excluded from the study because they could not be clearly differentiated due to AF attack or chronic diseases. Our inclusion criteria were complete left bundle branch block presence on ECG, EF < 35\%, and taking optimal medical therapy but still New York Heart Association (NYHA) Class 3-4 functional capacity. As a result, we included 181 patients in our retrospective study.

\section{Laboratory assessment}

Kidney functions, lipid levels, high-sensitivity C-reactive protein (hs-CRP), uric acid, N-terminal pro-natriuretic peptide (NT-proBNP), thyroid functions, and complete blood count were recorded from blood taken at the time of admission.

\section{Electrocardiographic and echocardiographic assessment}

Twelve-lead surface ECGs of all patients were recorded by a MAC 2000 ECG Machine (GE Medical Systems Information Technologies, Inc., WI, USA) before the CRT-D implantation. Electrocardiograms had $25 \mathrm{~mm} / \mathrm{s}$ speed and $1 \mathrm{mv} / 10 \mathrm{~mm}$ standard calibration. The onset and end of the $P$ wave were defined as the point of the first visible upward slope from the isoelectric line and the point of return to the isoelectric line, respectively. The PR interval was defined as the time from the onset of the $P$ wave to the start of the QRS complex. The PWD is the duration between those points measured in the DII lead of a 12-lead ECG, in milliseconds. Two independent cardiologists assessed these parameters. PWDI was calculated by dividing the PWD by the PR interval in the DII lead of 12-lead ECG (Figures $1 \mathrm{~A}-\mathrm{C}$ ). P-wave dispersion (Pdisp) is the difference between the maximum and minimum PWD on a 12-lead ECG. First-degree (partial) interatrial block (IAB) was determined with two previously defined criteria [12]: (a) P wave of $120 \mathrm{~ms}$ or more, usually bimodal, which is especially visible in leads I, II, or III; and (b) the P-wave morphology in V1 presenting a P-wave negative mode. Third-degree (advanced) IAB was determined with two previously defined criteria (9): (a) P-wave duration 120 ms or more; and (b) the morphology of $P$ wave is usually bimodal in leads I, and AVL, and biphasic in leads II, III, and AVF, and in V1 and V2. Echocardiographic examinations were performed using an Epiq 7 (Philips Healthcare, DA Best, Netherlands) echocardiography system before CRT implantation. EF, left ventricle diastolic diameter (LVDD), left ventricle systolic diameter (LVSD), left atrium diameter (LAD), left atrium area (LAA), left atrium volume (LAV), and left atrium volume index (ILAV) were measured and recorded. Left atrium volume index (ILAV) was calculated as LAV divided by the body 
A

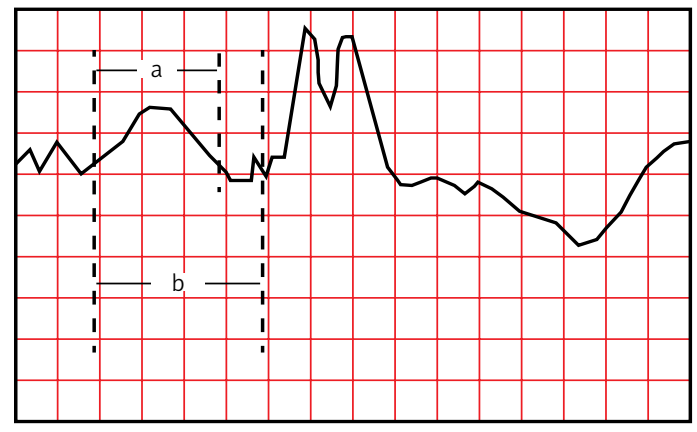

C

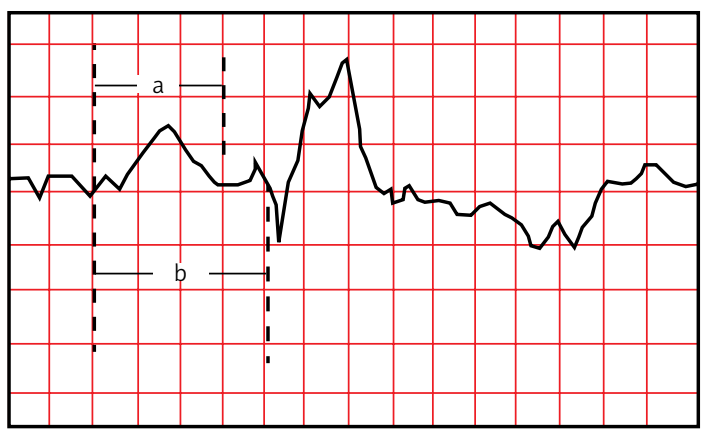

mass index. The interobserver compatibility was $96 \%$ in these measurements.

\section{Cardiac resynchronisation therapy device implantation}

The CRT-D devices used were manufactured by Medtronic, Inc. The coronary sinus lead (Medtronic Inc., Minneapolis, MN, USA) was placed in the basal or mid-segment of a lateral or posterior vein. The right atrial lead (Medtronic Inc., Minneapolis, MN, USA) was placed in the right atrial appendage, and the right ventricular lead (Medtronic Inc., Minneapolis, MN, USA) was placed in the mid-septum or apex. Patients with sinus rhythm were set to DDD-mode (lower rate limit 50) to achieve atri-
B

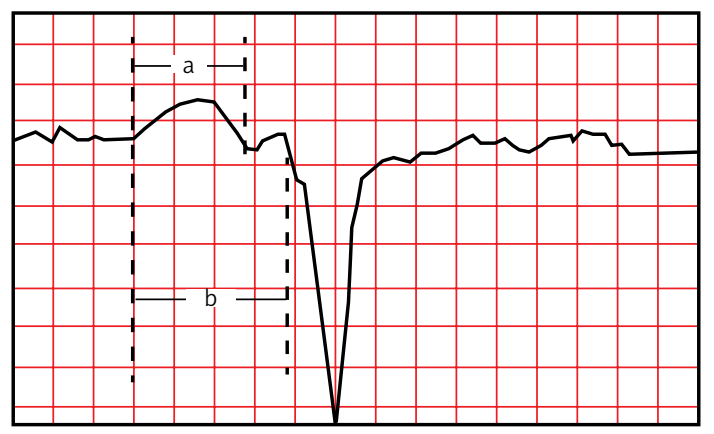

Figure 1. Demonstration of P-wave duration index on surface ECG in three different patients with cardiac resynchronisation therapy

al synchronous biventricular pacing. Devices were programmed with pacing mode DDD to maximise biventricular pacing. VV delay was set nominally at $0 \mathrm{~ms}$.

\section{Device and clinical evaluation, silent $\mathrm{AF}$ definitions}

Device interrogations were performed 1, 6, and 12 months after implantation and then also every 6 months. Device atrial stimulation/sense parameters, atrial lead impedance, percentages of atrial and ventricular pacing, automatic mode switch episodes, and noise episodes were recorded. The AF attacks that lasted for at least $30 \mathrm{~s}$ with no symptoms were accepted as silent AF

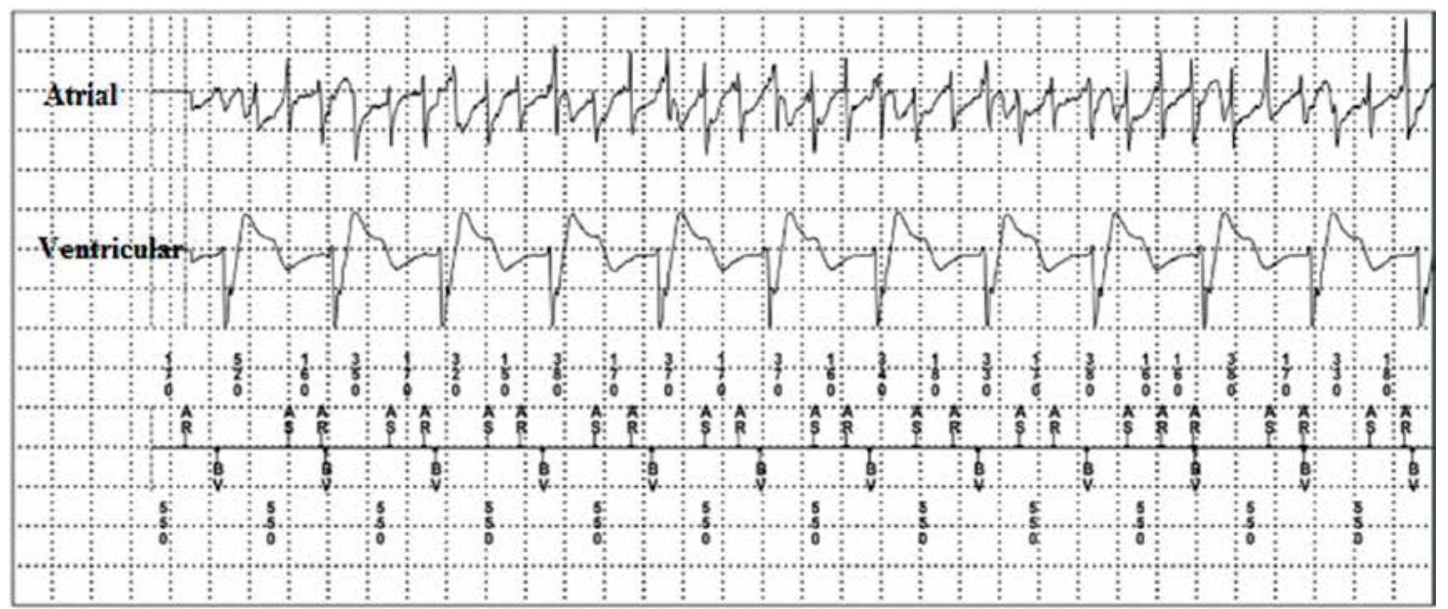

Figure 2. Silent atrial fibrillation episode from intracardiac EGM record 
(Figure 2). Every arrhythmia in the device memory was interpreted by two experienced physicians. A clinical evaluation was also performed including symptoms, outpatient or emergency department admissions, changes in antiarrhythmic and antithrombotic treatment, ECG documentation of $A F$, and mortality. Patients with these conditions were accepted as overt AF and excluded from the study (14 patients).

\section{Statistical analysis}

Variables were divided into categorical and continuous groups. Categorical variables were expressed as numbers and percentages. The $\chi^{2}$ test was used to analyse categorical variables. Continuous variables were shown as mean and standard deviation. The Kolmogorov-Smirnov test was used to determine whether continuous variables had normal distribution. Normally distributed variables were analysed with the independent samples $t$-test. Non-normally distributed variables were analysed with the Mann-Whitney $U$ test. Independent predictors for silent AF were determined by binomial logistic regression analysis using $p<0.05$ variables. Receiver operating characteristic (ROC) analysis was used to calculate cut-off, sensitivity, and specificity values of the independent silent AF predictors. The SPSS for Windows 20.0 Program (SPSS, Chicago, IL, USA) was used for statistical analysis. A $p$-value $<0.05$ was considered to be statistically significant.

\section{Results}

Patients were separated into two groups: "with silent AF" and "without silent AF". The without silent AF group comprised 121 patients (mean age: $62.9 \pm 8.7$ years, $62 \%$ male). The with silent AF group included 60 patients (mean age: 67.9 \pm 9.7 years, $60 \%$ male). The mean follow-up period was $30.2 \pm 10.8$ months. The first silent AF attack was detected 34 days after CRT implantation. The mean silent AF detection time was 155 \pm 112 days. The mean number of attacks was 1.8 \pm 0.5 , and the longest attack duration was one $1 \mathrm{~h}$ $20 \mathrm{~min}$. Atrial high rate episode was detected in 16 patients. There were no inappropriate shocks on routine CRT-D controls. The silent AF group had significantly higher mean age $(p=0.001)$. We found no other significant variable in the demographics, medications, and laboratory results ( $\mathrm{Ta}$ ble I). PR duration was significantly longer in the without silent AF group $(p=0.001)$. Patients with first-degree $I A B$ and $P W D I$ values were significantly higher in the with silent AF group ( $p$-values were 0.001 and $<0.001$, respectively). Other ECG and echocardiographic findings were similar (Table II). Age $(\mathrm{OR}=1.073,95 \% \mathrm{Cl}: 1.028-1.119, p=0.001)$ and PWDI (OR = 1.053, 95\% Cl: 1.028-1.078, $p<$ 0.001 ) were detected as independent predictors for silent $A F$ in the binomial logistic regression analysis (Table III). PWDI cut-off, sensitivity, and specificity values were determined for the prediction of silent AF in the ROC analysis (AUC $=0.701$, $p<0.001$, Figure 3).

\section{Discussion}

The most important finding of our study is the statistically significant relation between PWDI and silent AF. When the PWDI cut-off value was taken as 0.67 , the specificity was $81.7 \%$ and the sensitivity was $51.4 \%$. Also, age is another significant factor in silent AF development.

Silent AF can be determined incidentally from an inpatient visit, a thorough physical examination, or preoperative assessments. Silent AF patients can sometimes also have AF complications like stroke or congestive heart failure [13]. These patients can be asymptomatic, but it should not be interpreted as there not being any AF complications. Two large studies emphasised the prognostic value and told that silent AF had the same risk as symptomatic $A F[14,15]$. It was reported that the $37 \%$ yearly incidence of $A F$ in pacemaker-implanted patients and anticoagulant usage was less than expected (58\%) despite $77 \%$ of patients having $\mathrm{CHADS}_{2}$ score $\geq 2$ [16]. We collected optimal rhythm records because our patient group had CRT-D devices. Silent AF was found in $61(33.7 \%)$ patients. The silent AF probability was higher than normal because all of our patients had HF. $\mathrm{CHA}_{2} \mathrm{DS}_{2}$-VASc score may be calculated, and anticoagulant therapy may be initiated in suitable patients. It is essential to identify silent AF and initiate the anticoagulant therapy before any complications, because the mortality and morbidity are the same as for symptomatic AF. Silent AF-detected patients are at higher risk of stroke and mortality due to HF and AF.

Remodelling starts with the sodium and calcium channels of the left atrium and pulmonary venous tissue cells in the setting of inflammation and oxidative parameters. Electrical stability starts to decrease, and irregular electrical activity, called atrial heterogeneity, starts to happen. Fibroblast proliferation, inflammation, and apoptosis start to develop as predisposing factors of AF [17]. The investigators described Bayes syndrome, which is characterised by interatrial conduction delay or block [18]. According to them, it is predisposing for the supraventricular arrhythmias to have PWD $\geq 120 \mathrm{~ms}$ in DII, DIII and aVF leads. Third-degree IAB (PWD $\geq 120 \mathrm{~ms}$ and biphasic $P$ wave) are seen frequently in the elderly even when there is no LAE [19]. Also, it has been shown as a marker of AF, cardiovascular, and all-cause mortality [20]. In 
Abdullah Orhan Demirtas, Yahya Kemal Icen, Yurdaer Donmez, Hasan Koca, Onur Kaypakli, Mevlut Koc

Table I. Comparison of patients' demographics, medications, and laboratory findings

\begin{tabular}{|c|c|c|c|}
\hline Parameter & $\begin{array}{l}\text { Patients with silent AF } \\
\qquad(n=60)\end{array}$ & $\begin{array}{l}\text { Patients without silent AF } \\
\qquad(n=121)\end{array}$ & $P$-value \\
\hline Age [years] & $67.9 \pm 9.7$ & $62.9 \pm 8.7$ & 0.001 \\
\hline Male gender, $n(\%)$ & $36(60.0)$ & $75(62.0)$ & 0.796 \\
\hline Systolic blood pressure [mm Hg] & $120.6 \pm 16.0$ & $121.1 \pm 17.1$ & 0.878 \\
\hline Diastolic blood pressure [mm Hg] & $77.1 \pm 11.2$ & $76.2 \pm 10.7$ & 0.968 \\
\hline Pulse [beats/min] & $76.4 \pm 12.1$ & $78.3 \pm 10.9$ & 0.297 \\
\hline $\mathrm{BMI}\left[\mathrm{kg} / \mathrm{m}^{2}\right]$ & $26.3 \pm 3.8$ & $26.8 \pm 3.2$ & 0.440 \\
\hline Smoking, $n(\%)$ & $9(15.0)$ & $17(14.0)$ & 0.864 \\
\hline DM, n (\%) & $27(45.0)$ & $53(43.8)$ & 0.879 \\
\hline $\mathrm{HT}, n(\%)$ & $38(63.3)$ & $66(54.5)$ & 0.260 \\
\hline HPL, $n(\%)$ & $35(58.3)$ & $52(43.0)$ & 0.052 \\
\hline Ischaemic CMP, $n$ (\%) & $25(41.7)$ & $51(42.1)$ & 0.951 \\
\hline ACE, $n(\%)$ & $43(71.7)$ & $75(62.0)$ & 0.198 \\
\hline $\mathrm{ARB}, n(\%)$ & $10(16.7)$ & $25(20.7)$ & 0.522 \\
\hline$\beta$-Blocker, $n(\%)$ & $55(91.7)$ & $113(93.4)$ & 0.673 \\
\hline Furosemide, $n$ (\%) & $55(91.7)$ & $104(88.5)$ & 0.268 \\
\hline Spironolactone, $n(\%)$ & $44(36.4)$ & $77(63.6)$ & 0.857 \\
\hline Ivabradine, $n(\%)$ & $14(23.3)$ & $21(17.4)$ & 0.338 \\
\hline Digoxin, $n(\%)$ & $18(30.0)$ & $26(21.5)$ & 0.209 \\
\hline ASA, $n(\%)$ & $35(58.3)$ & $75(62.0)$ & 0.636 \\
\hline WBC $[\mu l]$ & $8.2 \pm 2.4$ & $8.2 \pm 2.3$ & 0.962 \\
\hline Htc (\%) & $37.8 \pm 4.5$ & $38.7 \pm 5.2$ & 0.284 \\
\hline BUN [mg/dl] & $55.6 \pm 34.2$ & $50.5 \pm 30.3$ & 0.302 \\
\hline $\mathrm{Cr}[\mathrm{mg} / \mathrm{dl}]$ & $1.1 \pm 0.5$ & $1.3 \pm 1.2$ & 0.287 \\
\hline $\mathrm{Na}[\mathrm{mmol} / \mathrm{l}]$ & $137.4 \pm 3.9$ & $137.1 \pm 4.1$ & 0.654 \\
\hline $\mathrm{K}[\mathrm{mmol} / \mathrm{l}]$ & $4.6 \pm 0.6$ & $4.6 \pm 0.5$ & 0.832 \\
\hline Total cholesterol [mg/dl] & $180.2 \pm 46.9$ & $166.6 \pm 43.8$ & 0.056 \\
\hline $\mathrm{LDL}[\mathrm{mg} / \mathrm{dl}]$ & $113.1 \pm 34.1$ & $105.5 \pm 35.6$ & 0.169 \\
\hline $\mathrm{HDL}[\mathrm{mg} / \mathrm{dl}]$ & $38.5 \pm 9.6$ & $37.9 \pm 13.3$ & 0.780 \\
\hline Triglyceride [mg/dl] & $143.8 \pm 74.4$ & $163.2 \pm 102.3$ & 0.149 \\
\hline $\mathrm{Hs}-\mathrm{CRP}[\mathrm{mg} / \mathrm{l}]$ & $2.3 \pm 2.6$ & $2.4 \pm 2.9$ & 0.782 \\
\hline Uric acid [mg/dl] & $7.1 \pm 2.2$ & $6.9 \pm 2.2$ & 0.607 \\
\hline NT-proBNP [pg/ml] & $677.7 \pm 579.3$ & $612.1 \pm 654.4$ & 0.510 \\
\hline $\mathrm{T} 4$ [ng/dl] & $1.3 \pm 0.2$ & $1.3 \pm 0.3$ & 0.626 \\
\hline TSH [ulU/dl] & $1.9 \pm 1.2$ & $1.9 \pm 1.5$ & 0.803 \\
\hline
\end{tabular}

$A F$ - atrial fibrillation, BMI - body mass index, CMP - cardiomyopathy, DM - diabetes mellitus, HT - hypertension, HPL - hyperlipidaemia, $A C E$ - angiotensin-converting enzyme, ARB - angiotensin receptor blocker, ASA - acetylsalicylic acid, BUN - blood urea nitrogen, $\mathrm{Cr}$-creatinine, $\mathrm{HDL}$ - high density lipoprotein, $\mathrm{Hs}$-CRP - high-sensitivity C-reactive protein, Htc-haematocrit, IQR - interquartile range, $L D L$ - low-density lipoprotein, TSH - thyroid-stimulation hormone, NT-proBNP - N-terminal brain natriuretic peptide, WBC-white blood cells. 
Table II. Comparison of electrocardiographic and echocardiographic findings

\begin{tabular}{|lccc|}
\hline Parameter & $\begin{array}{c}\text { Patients with silent AF } \\
(n=60)\end{array}$ & $\begin{array}{c}\text { Patients without silent AF } \\
(n=121)\end{array}$ & $P$-value \\
\hline EF $(\%)$ & $25.5 \pm 5.9$ & $24.9 \pm 5.9$ & 0.540 \\
\hline LVDD $[\mathrm{mm}]$ & $59.5 \pm 9.6$ & $60.2 \pm 10.2$ & 0.655 \\
\hline LVDS [mm] & $59.5 \pm 9.6$ & $60.2 \pm 10.2$ & 0.655 \\
\hline LAD [mm] & $42.1 \pm 4.1$ & $42.5 \pm 4.4$ & 0.508 \\
\hline LAA [mm $\left.{ }^{2}\right]$ & $21.1 \pm 4.3$ & $21.8 \pm 4.1$ & 0.287 \\
\hline LAV [mm $\left.{ }^{3}\right]$ & $82.2 \pm 18.9$ & $82.0 \pm 18.3$ & 0.959 \\
\hline ILAV [ml/m $]$ & $45.7 \pm 11.6$ & $43.8 \pm 10.3$ & 0.253 \\
\hline QRS [ms] & $151.5 \pm 17.3$ & $152.3 \pm 16.8$ & 0.762 \\
\hline PR [ms] & $141.2 \pm 17.9$ & $157.0 \pm 27.8$ & $<0.001$ \\
\hline PWD [ms] & $112.4 \pm 10.6$ & $108.3 \pm 13.4$ & 0.03 \\
\hline First degree IAB, $n(\%)$ & $20(\% 33.6)$ & $16(13.2)$ & 0.001 \\
\hline Pdisp [ms] & $32.8 \pm 15.7$ & $30.3 \pm 11.2$ & 0.540 \\
\hline PWDI & $0.81 \pm 0.14$ & $0.70 \pm 0.13$ & $<0.001$ \\
\hline
\end{tabular}

$A F$ - atrial fibrillation, EF - ejection fraction, ILAV - indexed left atrial volume, LVDD - left ventricular end diastolic diameter, LAD - left atrial diameter, LAV - left atrial volume, Pdisp - P-wave dispersion, $P W D-P$-wave duration, $P W D I-P$-wave duration index.

Table III. Independent predictors for silent AF

\begin{tabular}{|lccc|}
\hline Parameter & Odds ratio & $95 \%$ confidence interval & $P$-value \\
\hline Age & 1.073 & $1.028-1.119$ & 0.001 \\
\hline PWD & 0.988 & $0.954-1.023$ & 0.489 \\
\hline PR & 0.948 & $0.871-1.032$ & 0.216 \\
\hline PWDI & 1.053 & $1.028-1.078$ & $<0.001$ \\
\hline
\end{tabular}

$P W D$ - P-wave duration, PWDI - P-wave duration index.

studies advanced IAB is not found commonly in the general population but reported as a risk factor for AF. First-degree IAB frequency was 33\% in our silent AF patients [21]. It was not an independent factor for AF, but it is significantly high in the silent AF group. It is also compatible with previous studies.

The P-wave duration reflects the distance of electrical activity from the sinus node to the atrioventricular junction. If the distance is long, then the PWD length is approximately the same amount. Prolonged PWD was found to be significantly related to AF in the patients over 60 years old according to the Framingham study [22]. Some researcher found that $\mathrm{P}$-wave variance is related to paroxysmal AF [23]. They claimed that the increased P-wave variance reflects the non-homogeneous spreading of sinus waves in the atrium. P-wave dispersion is a risk factor for $\mathrm{AF}$ and projects the atrial electrical heterogeneity. It is said that increased Pdisp is a risk factor for the degeneration of paroxysmal AF to persistent $A F$ [24]. All of our patients had HF. All heart chambers were dilated in these patients. Left atrium

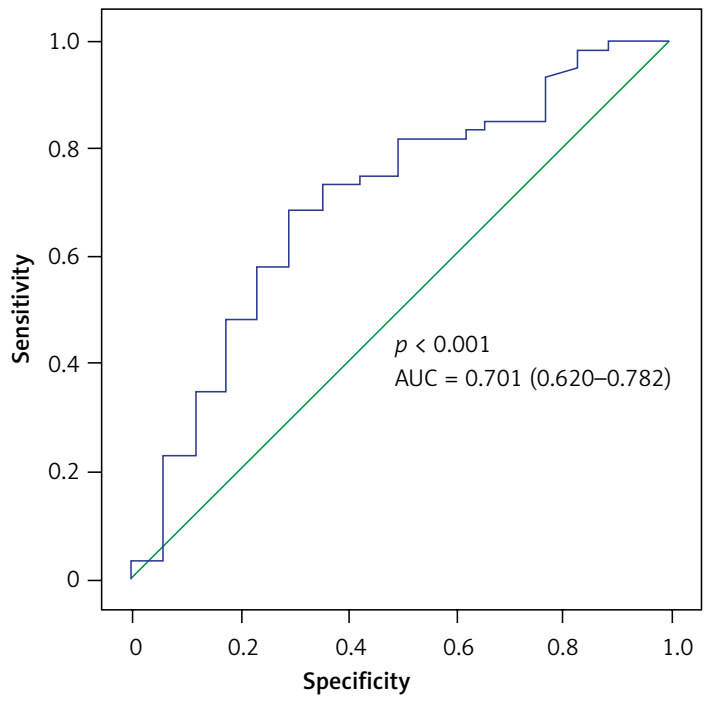

\begin{tabular}{|lcc|}
\hline Cut-off & Specificity (\%) & Sensitivity (\%) \\
\hline 0.67 & 81.7 & 51.4 \\
\hline 0.69 & 75 & 57.9 \\
\hline 0.78 & 55 & 76.9 \\
\hline
\end{tabular}

Figure 3. ROC analysis to determine sensitivity and specificity of P-wave duration index for silent AF 
sizes were also increased. Therefore, both PWD and Pdisp were higher in the silent AF group, but there was no statistical significance. Even these two parameters were determined higher than the normal population; we do not think that they will be predictors for AF in HF patients. Thus, PWD and Pdisp cannot be used as predictors of AF in our patients. There should be more sensitive markers than PWD and Pdisp for HF patients with silent AF.

Some parameters, such as atrioventricular delay ( $\mathrm{A}-\mathrm{V}$ delay) and interventricular delay ( $\mathrm{V}-\mathrm{V}$ delay), can be adjusted via the CRT-D device. The $P R$ interval will be prolonged with the increased A-V delay. Eventually, this will change the PWDI value. Therefore, we excluded patients with atrial pacing. $\beta$-blockers are basically effective over the A-V node. There was over $90 \% \beta$-blocker usage in both of our groups, and there was no statistical difference. We thought that the $\beta$-blocker effect over PWDI was the same in both groups. We also consider that increasing the $\beta$-blocker dose will result in the prolonged P-R interval and decreased PWDI value. Thus, silent AF attacks may be diminished.

In a recent study, it was reported that PWDI was a marker for the recurrence in cryoballoon ablation applied patients, and it was found to be relative to the LAV [11]. We found a statistically significant relationship between PWDI and silent AF. Also, it could determine silent AF with relatively high specificity. In our opinion, PWDI is more sensitive for the prediction of silent AF than PWD and Pdisp because it is a ratio of two parameters. Silent AF is diagnosed incidentally, so PWDI can be useful for protection from stroke and mortality in these patients. We think that the calculation of PWDI should be applied after the CRT-D implantation, as our patients. We consider that if we can reduce PWDI value under the cut-off limits by changing the $A-V$ delay or using $\beta$-blocker therapy, then silent $A F$ attacks might be diminished.

PR interval, P-wave axis, maximum area and duration, terminal force, and Pdisp are defined as P-wave indices, and they are affected by the patients' current situation [25]. It was reported in a study that only PR interval is consistent and all other parameters are variable in the 1-2 weeks of periodical ECGs. It can be misleading to use only one of these variable parameters when predicting the patient's clinical situation. We think it can be more sensitive to use the ratio of at least two parameters.

There were several limitations to our study. The patient number was relatively low compared to other studies [26]. P-wave axis and area, which reflects the atrial heterogeneity, were not calculated. Calculated ECG parameters were not correlated with other ECGs. There is a clear need for randomised studies including more patients, in order to show whether PWDI is a predictor for silent AF.

In conclusion, PWDI is significantly associated with silent $A F$ in patients with CRT-D. Silent $A F$ risk can be determined and diminished with beta-blocker therapy or prolongation of $\mathrm{A}-\mathrm{V}$ delay. Physicians can adjust A-V delay, and so may reduce silent AF in CRT patients. Therefore, mortality and morbidity may be reduced in these patients.

\section{Conflict of interest}

The authors declare no conflict of interest.

\section{References}

1. Brignole M, Auricchio A, Baron-Esquivias G, et al. 2013 ESC Guidelines on cardiac pacing and cardiac resynchronization therapy: the Task Force on cardiac pacing and resynchronization therapy of the European Society of Cardiology (ESC). Developed in collaboration with the European Heart Rhythm Association (EHRA). Eur Heart J 2013; 34: 2281-329.

2. Haim M, Hoshen M, Reges O, Rabi Y, Balicer R, Leibowitz $M$. Prospective national study of the prevalence, incidence, management, and outcome of a large contemporary cohort of patients with incident non-valvular atrial fibrillation. J Am Heart Assoc 2015; 4: e001486.

3. Kirchhof P, Benussi S, Kotecha D, et al. 2016 ESC Guidelines for the management of atrial fibrillation developed in collaboration with EACTS. Eur Heart J 2016; 37: 2893-962.

4. Xiong Q, Proietti M, Senoo K, Lip GY. Asymptomatic versus symptomatic atrial fibrillation: a systematic review of age/gender differences and cardiovascular outcomes. Int J Cardiol 2015; 191: 172-7.

5. Sparks PB, Mond HG, Kalman JM, Jayaprakash S, Lewis MA, Grigg LE. Atrial fibrillation and anticoagulation in patients with permanent pacemakers: implications for stroke prevention. PACE 1998; 21: 1258-67.

6. Nielsen JC. Mortality and incidence of atrial fibrillation in paced patients. J Cardiovasc Electrophysiol 2002; 13: 17-22.

7. Davis RC, Hobbs FD, Kenkre JE, et al. Prevalence of atrial fibrillation in the general population and in high-risk groups: the ECHOES study. Europace 2012; 14: 1553-9.

8. Baranchuk A, Parfrey B, Lim L, et al. Interatrial block in patients with obstructive sleep apnea. Cardiol J 2011; 18: 171-5.

9. Enriquez A, Conde D, Hopman W, et al. Advanced interatrial block is associated with recurrence of atrial fibrillation post pharmacological cardioversion. Cardiovasc Ther 2014; 32: 52-6.

10. Mirvis DM, Goldberger AL. Electrocardiography. In: Braunwald's Heart Disease: A Textbook of Cardiovascular Medicine. Mann DL, Zipes DP, Libby P, Bonow RO, Braunwald E (ed.). 10 $10^{\text {th }}$ edition. Elsevier 2015; 114-54.

11. Kaypakli O, Koca H, Şahin DY, Okar S, Karataş F, Koç M. Association of $\mathrm{P}$ wave duration index with atrial fibrillation recurrence after cryoballoon catheter ablation. J Electrocardiol 2018; 51: 182-7.

12. Bayés de Luna A, Platonov P, Cosio FG, et al. Interatrial blocks. A separate entity from left atrial enlargement: a consensus report. J Electrocardiol 2012; 45: 445-51. 
13. Savelieva I, Camm AJ. Clinical relevance of silent atrial fibrillation: prevalence, prognosis, quality of life, and management. J Interv Card Electrophysiol 2000; 4: 369-82.

14. Wyse DG, Waldo AL, DiMarco JP, et al.; Atrial Fibrillation Follow-up Investigation of Rhythm Management (AFFIRM) Investigators. A comparison of rate control and rhythm control in patients with atrial fibrillation. $\mathrm{N}$ Engl J Med 2002; 347: 1825-33.

15. Van Gelder IC, Hagens VE, Bosker HA, et al.; Rate Control versus Electrical Cardioversion for Persistent Atrial Fibrillation Study Group. A comparison of rate control and rhythm control in patients with recurrent persistent atrial fibrillation. N Engl J Med 2002; 347: 1834-40.

16. Cabrera S, Mercé J, de Castro R, et al. An opportunity to detect silent atrial fibrillation and improve antithrombotic treatment. Europace 2011; 13: 1574-9.

17. Youn JY, Zhang J, Zhang Y, et al. Oxidative stress in atrial fibrillation: an emerging role of NADPH oxidase. J Mol Cell Cardiol 2013; 62: 72-9.

18. Bayes de Luna A, Conde D, Baranchuk A. Advanced interatrial block as a substrate of supraventricular tachyarrhythmias: a well-recognized syndrome. J Electrocardiol 2015; 48: 133-4.

19. Spodick DH, Ariyarajah V. Interatrial block. The pandemic remains poorly perceived. Pacing Clin Electrophysiol 2009; 32: 667-72.

20. Magnani JW, Gorodeski EZ, Johnson VM, et al. P wave duration is associated with cardiovascular and all-cause mortality outcomes: the National Health and Nutrition Examination Survey. Heart Rhythm 2011; 8: 93-100.

21. O'Neal WT, Zhang ZM, Loehr LR, Chen LY, Alonso A, Soliman EZ. Electrocardiographic advanced interatrial block and atrial fibrillation risk in the general population. Am J Cardiol 2016; 117: 1755-9.

22. Magnani JW, Johnson VM, Sullivan LM, et al. P wave duration and risk of longitudinal atrial fibrillation in persons $\geq 60$ years old (from the Framingham Heart Study). Am J Cardiol 2011; 107: 917-21.

23. Andrikopoulos GK, Dilaveris PE, Richter DJ, Gialafos EJ, Synetos AG, Gialafos JE. Increased variance of $P$ wave duration on the electrocardiogram distinguishes patients with idiopathic paroxysmal atrial fibrillation. Pacing Clin Electrophysiol 2000; 23: 1127-32.

24. Dilaveris PE, Gialafos JE. P-wave dispersion: a novel predictor of paroxysmal atrial fibrillation. Ann Noninvasive Electrocardiol 2001; 6: 159-65.

25. Snyder ML, Soliman EZ, Whitsel EA, Gellert KS, Heiss G. Short-term repeatability of electrocardiographic $P$ wave indices and PR interval. J Electrocardiol 2014; 47: 257-63.

26. Agarwal YK, Aronow WS, Levy JA, Spodick DH. Association of interatrial block with development of atrial fibrillation. Am J Cardiol 2003; 91: 882. 